\title{
Energetic efficiency of the utilization of acetic acid and glycerol by fattening sheep*
}

\author{
By J. ROBB† AND J. T. REID \\ Department of Animal Science, Cornell University, \\ Ithaca, New York, USA
}

(Received 2 November I97I - Accepted I8 February 1972)

\begin{abstract}
I. Experiments were undertaken: to measure the efficiency of utilization of acetate (equimolar amounts of acetic acid and sodium acetate) for body-energy gain in sheep; to determine the effect of glycerol on acetate utilization; to compare the energetic efficiencies of sheep into which acetate or glycerol or a combination of the two was intraruminally infused continuously throughout the $24 \mathrm{~h}$ or rapidly during two intervals of $\mathrm{I} h$ each after feeding with the basal diet each day; to examine the relationship of the length of the infusion period to the efficiency with which the additives were utilized.

2. Complete energy balances were derived with two mature, cross-bred, rumen-cannulated wethers given a basal diet of pelleted lucerne hay at just above the maintenance level in two meals/d at $x 2 \mathrm{~h}$ intervals. During all the periods in which acetate was not infused, saline was infused to provide an equivalent amount of cation.

3. The methods of infusing the additives or the additives themselves had essentially no effect on the apparent digestibility of dietary energy or nitrogen. Also, methane production was not adversely influenced by the additives infused.

4. Urinary nitrogen losses were lower and nitrogen retention was greater when acetate or glycerol, or both, were infused than when saline was infused.

5. The calorimetric efficiency with which the additives were utilized for body gain was significantly $(P<0.05)$ affected by the method of infusion. When acetate alone was infused the efficiencies for the continuous and rapid infusions were 63.0 and $5 \mathrm{r} \cdot 8 \%$ respectively. The efficiencies with which glycerol was utilized when it was infused continuously and when it was infused rapidly were $70 \cdot 3$ and $62.2 \%$ respectively.

6 . When acetate was infused in the presence of glycerol, the respective efficiencies of the acetate (not including those of glycerol) were 68.1 and $57.9 \%$ for the continuous and rapid infusions respectively. "The efficiencies with which the total energy of the acetate + glycerol was utilized were 68.8 and $58.6 \%$ for the continuous and rapid infusions respectively.

7. The only instance in which there was a change in energetic efficiency with the length of the infusion period was that involving the rapid infusion of acetate in the presence of glycerol. The efficiency increased progressively throughout the experimental period and by the 28th day of infusion there was no difference in efficiency attributable to the method of infusion.
\end{abstract}

It is well known that the absorbed volatile fatty acids (VFA) resulting from ruminal fermentation are significant sources of energy in the ruminant. However, the results of experiments concerned with the relative efficiency with which the various VFA are utilized have given a confused picture.

In the short-term calorimetric experiments conducted at the Hannah Institute (Armstrong \& Blaxter, 1956, 1957a, b, 1961; Armstrong, Blaxter \& Graham, I957, I961; Armstrong, Blaxter, Graham \& Wainman, 1958), acetic acid was found to be the greatest contributor to the high heat increment associated with the utilization of the metabolites arising from microbial fermentation in the sheep. Those

* These investigations were supported in part by Research Grant No. AM-02889 from the National Institute of Arthritis and Metabolic Diseases, US Public Health Service, Bethesda, Maryland, USA.

$\uparrow$ Present address: Unilever Research Laboratory, Colworth House, Sharnbrook, Bedfordshire. 
investigators observed that the net efficiencies (\%) with which the metabolizable energy (ME) of the VFA infused singly into the rumen of sheep receiving a maintenance ration was utilized for fattening were: acetic acid, $32 \cdot 9$; propionic acid, $56 \cdot 3$; $n$-butyric acid, $6 \mathrm{I} \cdot 9$. However, in longer-term experiments, in which body energy was determined by whole-body analysis (Elliot, Hogue, Myers \& Loosli, I965), or by body-weight gains alone or in combination with body specific gravity (Ørskov \& Allen, I966 a, $b, c$; Ørskov, Hovell \& Allen, 1966), the efficiency with which the energy provided by acetic acid was utilized for body-energy gain by sheep appeared to be similar to that provided by propionate or butyrate.

Recently, Bull, Reid \& Johnson (I970), using a $175 \mathrm{~d}$ feeding period and a slaughter, direct-analysis experiment, observed that sheep given a basal diet supplemented with triacetin gained body energy as efficiently as did their control mates given the basal diet supplemented with an amount of glycerol equivalent to that in the triacetin. The efficiency with which the metabolized acetate was utilized for fattening was $71 \cdot 2 \%$. The same authors also reported some preliminary observations made in respirationcalorimetric experiments which suggested that, when sheep are subjected to an abrupt influx of acetic acid, the efficiency with which the acetic acid is utilized may be low for several days after the initiation of continuous infusion, but that it improves markedly by the $I_{5}$ th day.

The experiments to be described here were undertaken with sheep $(a)$ to examine the effect of glycerol on acetate utilization, (b) to compare the influence on energetic efficiency of rapid intraruminal infusions of glycerol and acetate delivered within I h after feeding with continuous infusions throughout $24 \mathrm{~h}$ of each day, and $(c)$ to determine the relationship of the duration of metabolite infusion to the energetic efficiency.

\section{EXPERIMENTAL}

Animals. Two animals were selected from a group of ten rumen-cannulated, Hampshire $\times$ Western wethers. The main bases of sclection were general health, condition of their rumen cannulas, and their temperament and performance as judged during a test period in the respiration calorimeter. At the start of the first experiment both sheep were approximately 2 years old and weighed $44 \mathrm{~kg}$.

Basal diet and additives. The basal diet given throughout all the experiments consisted of pelleted, ground lucerne preparcd from the same early-season harvest. On the dry basis, the pellets contained $19.55 \%$ protein, $2.40 \%$ ether extractives, $12.31 \%$ ash, $65.74 \%$ carbohydrates, and $4.295 \mathrm{kcal}(\mathrm{1} 7.97 \mathrm{~kJ})$ gross energy $/ \mathrm{g}$. The basal diet was provided in two equal meals each day at $\mathrm{i} 2 \mathrm{~h}$ intervals. Water and trace-mineralizcd salt were freely available.

According to a prescribed sequence, described below, one or two of the following additives were infused intraruminally in 41 of liquid per $24 \mathrm{~h}$ during a given interval: a mixture of equimolar amounts of acetic acid (J. T. Baker Chemical Co., Phillipsburg, NJ) and sodium acetate (Allied Chemical Corp., Morristown, NJ); glycerol (ColgatePalmolive Co., New York, NY); and sodium chloride (Allied Chemical Corp., Morristown, NJ). All these additives were of 'Reagent Grade' or 'chemically pure' quality. 
Experimental plan. Four trials characterized by specific sequences of intraruminal infusions were carried out. Trials I and 2 constituted Expt I, and trials 3 and 4 made up Expt 2. Within a given trial, one sheep was subjected to a continuous uniform infusion of the same additive that was administered to the other sheep by a rapid infusion during the $\mathrm{I} h$ period immediately after feeding with the basal diet. The second trials of each experiment (i.e. trials 2 and 4 ) were replicates of the first trials (i.e. trials $\mathrm{I}$ and 3 ), except that each animal was subjected to the alternate method of infusion. The desired infusion flow-rate was effected by pumps (Sigmamotor Inc., Middleport, NY) with a rotating eccentric cam exerting pressurc on resilient gum-latex tubing through which the fluids were forced.

In trials $I$ and 2 the following sequence of periods and their duration were imposed: saline control, I2 d; acetate, $28 \mathrm{~d}$; saline recovery, $\mathrm{I} 2 \mathrm{~d}$. Trials 3 and 4 consisted of the following order and duration of periods: saline control, I2 d; glycerol + saline control, I 2 d; glycerol + acetate, 28 d; glycerol + saline recovery, $12 \mathrm{~d}$; saline recovery, $12 \mathrm{~d}$.

During the saline-control and recovery periods, the amount of $\mathrm{NaCl}$ infused supplied the same amount of cation provided by the sodium acetate in the acetateacetic acid mixturc infused during the other periods. In all the trials, the total volume of liquîd infused was $4 \mathrm{l} / 24 \mathrm{~h}$; in the rapid infusion treatment, 21 were infused after each of the two meals each day.

The intake of the basal diet was held constant during trials 1,2 and 3 ; the mean intakes of gross energy by sheep I and 2 were $3687\left({ }^{\circ} 5^{\circ} 43\right)$ and $369^{8}\left({ }^{\circ} 5^{\circ} 47\right) \mathrm{kcal}(\mathrm{MJ}) / \mathrm{d}$ respectively. Before the beginning of trial 4 the intake of gross energy was increased to $4089 \mathrm{kcal}(\mathrm{I} 7 \cdot \mathrm{I} \mathrm{I} \mathrm{MJ}) / \mathrm{d}$ and maintained at that level throughout trial 4.

The amount of acetate-acetic acid infused was equivalent to $360 \mathrm{kcal}$ (I $506 \mathrm{~kJ}$ ) of gross energy per $\mathrm{d}$ in all four trials. The gross energy equivalent of the glycerol infused during trials 3 and 4 was $216 \mathrm{kcal}(904 \mathrm{~kJ}) / \mathrm{d}$.

Metabolism trials. During the acetate (trials $\mathrm{I}$ and 2 ) and acetate + glycerol (trials 3 and 4) infusion periods, faeces and urine were collected during two 6 or $8 \mathrm{~d}$ periods. During each of the other infusion periods, faeces and urine were collected during one 6 or $8 \mathrm{~d}$ trial.

Gaseous exchange measurements were made with each animal throughout $24 \mathrm{~h}$ periods on every $4^{\text {th }}$ day throughout each experiment by the method of indirect calorimetry described by Bull et al. (I970). A total of 130 individual-animal, $24 \mathrm{~h}$ energy balances were derived in these studies.

Sampling and analytical methods. Food and faeces samples were freeze-dried to constant weight, ground and later analysed for moisture (by freeze-drying), nitrogen, cther extract and ash according to the standard procedures outlined by the Association of Official Agricultural Chemists (r960). Urinary nitrogen was determined on wet samples. Heat of combustion was determined on the freeze-dried food, faeces and urine samples by means of an oxygen-bomb adiabatic calorimeter. 


\section{RESULTS}

Apparent digestibility of dietary energy. In Expt $\mathrm{I}$ the digestibilities of dietary energy during the saline infusion periods were $66.3 \pm 0.69$ and $65.5 \pm 0.53 \%$ for the continuous and rapid infusions respectively. The corresponding mean values and their standard errors during the acetate infusion periods (excluding the energy equivalent of the acetate-acetic acid mixture) were $65 \cdot x \pm 0.82$ and $66 \cdot 9 \pm 0.68 \%$ respectively.

In Expt 2 the digestibilities of the dietary energy for the continuous and rapid infusions during the various periods were: saline, $65 \cdot 6 \pm 0.40$ and $65.2 \pm 1.02 \%$; saline +glycerol, $64 \cdot 9 \pm 0.24$ and $65 \cdot 0 \pm 0.35 \%$; glycerol +acetate, $64.8 \pm 0.46$ and $64 \cdot 6 \pm 0.35 \%$ respectively.

The results from both experiments show that neither the method of infusion nor the kind of additive infused had any significant effect on the digestibility of the dietary energy. In experiments of this type in which metabolites are administered in addition to the basal diet, interpretation depends greatly on the assumption that the metabolism of the basal diet remains unchanged. This assumption seems valid in the present experiments since neither the apparent digestibility of energy nor the production of methane (discussed below) was adversely influenced by the infused additives.

Methane production. Owing to analytical difficulties during the first trial of Expt I the measurement of methane was unreliable and therefore the results for methane losses in that trial were discarded. For the estimates of energetic efficiency, to be discussed later, methane losses for trial I were estimated from those obtained in trial 2 with the same animals at the same level of intake of basal diet. Nevertheless, the results of the first experiment were not suitable for statistical analysis.

In Expt 2 the percentages of dietary energy lost as methane during the various periods under continuous and rapid infusions respectively were: saline, $5^{\cdot} 72 \pm 0.04$ and $5.78 \pm 0.07$; glycerol + saline, $5.88 \pm 0.08$ and $6.06 \pm 0.57$; glycerol + acetate $5.85 \pm 0.04$ and $5.91 \pm 0.12$. Although the methane loss was slightly greater for the rapid-infusion treatment, none of these differences was statistically significant. Disregarding the infusion methods used, the mean loss as methane during the glycerol + saline period $(5.97 \pm 0.06 \%)$ was significantly higher $(P<0.05)$ than that during the saline-control period $(5 \cdot 74 \pm 0.04 \%)$.

From the results obtained in trial 2 of Expt $\mathrm{I}$, it was estimated that $4 \cdot 18 \mathrm{kcal}$ $(175 \mathrm{~kJ}) / \mathrm{d}$, or $1 \cdot 16 \%$, of the gross energy of the acetate was lost as methane. In Expt 2 , from the difference between the observed methane losses during the periods in which the additives were infused and those expected to result from the basal diet, it was estimated that $9 \cdot 05 \mathrm{kcal}(37.9 \mathrm{~kJ}) / \mathrm{d}$, or $4 \cdot 19 \%$, of the gross energy of the glycerol was lost during the glycerol + saline infusion period and that only $5 \cdot 34 \mathrm{kcal}(22 \cdot 3 \mathrm{~kJ}) / \mathrm{d}$, or $0.93 \%$, of the gross energy of the combined additives was lost during the glycerol + acetate infusion period.

Apparent digestibility of dietary nitrogen. In Expt $\mathrm{x}$ the percentage of nitrogen apparently absorbed was not affected by either the method of infusion or the infused 
acetate. The digestion coefficients determined under the continuous- and rapidinfusion treatments during the saline-infusion periods were $73.7 \pm 0.6 \mathrm{r}$ and $72 \cdot 8 \pm 0.62 \%$ respectively, and during the acetate-infusion periods they were $73 \cdot 1 \pm 0.95$ and $74 \cdot I \pm 0.72 \%$ respectively.

In Expt 2 the apparent absorption of nitrogen was not affected by the method of infusion, but it was reduced slightly by the glycerol + acetate treatment. The percentages of nitrogen absorbed (ignoring method of infusion) during the various periods were: saline, $72 \cdot 7 \pm 0 \cdot 46$; saline + glycerol, $72 \cdot 0 \pm 0 \cdot 29$; glycerol + acetate, $7{ }^{1} 5 \pm 0 \cdot 17$. Although the difference in nitrogen digestibility between the saline period and the glycerol + acetate period was statistically significant $(P<0.05)$, the rather small difference seems biologically inconsequential.

Nitrogen retention. The method of infusion had no marked or consistent effect on the retention of dietary nitrogen. However, in both experiments, the main effect of the additives, irrespective of method of infusion, was one of enhanced nitrogen retention relative to that of the control treatment. Thus in Expt $r$ the nitrogen retention (expressed as a percentage of dietary intake) during the acetate period (12.93 \pm 0.77$)$ was significantly greater $(P<0.05)$ than that measured during the saline control period ( $9 \cdot 88 \pm \mathrm{r} \cdot 00$ ), and in Expt 2 the percentages of nitrogen retained during the saline, the glycerol+saline, and the glycerol +acetate periods were $5.99 \pm 0.96,7 \cdot 42 \pm 0.84$ and $9 \cdot 65 \pm 0.86$ respectively. In Expt 2 the retention during the glycerol + acetate period was significantly greater $(P<0.05)$ than that during the saline control period, but retention during the glycerol + saline period was not significantly different from that during the saline period $(P>0 \cdot r)$.

The observation that an increment of acetate added to a basal diet will enhance nitrogen retention has been well documented (Armstrong \& Blaxter, $1957 b$; Ørskov \& Allen, I $966 c$; Bull et al. 1970 ). However, it would seem that the enhanced retention is not peculiar to acetate alone, since Armstrong \& Blaxter (1957b) reported that propionic acid or butyric acid also enhanced nitrogen retention, but to a lesser extent. In the present experiment, the addition of glycerol also appeared to have a similar effect, though it lacked statistical significance.

Metabolizability of glycerol and acetate. The proportion of the gross energy of the additives that was metabolized was determined as the difference between the ME of the basal diet plus the additives and the ME of the basal diet plus saline. This difference divided by the gross energy value of the respective additives provided an estimate of the proportion of the respective additives metabolized.

In neither experiment did the method of infusion have a significant effect on the metabolizability of the acetate. The mean values for Expts $\mathrm{x}$ and 2 were $99.3 \pm 6.7 \%$ and $106 \cdot 0 \pm 2 \cdot 8 \%$ respectively. Since the general mean metabolizability of the acetate was $102.7 \%$ and since the standard error associated with the mean was relatively high $(3.6 \%)$, there was no justification for using any correction factor for the gross energy value of the acctatc in the calculation of the efficiency of utilization, to be discussed later. Thus, it was assumed that the metabolizability of acetate was $100 \%$.

As with that of acetate, the method of infusion of glycerol had no significant cffect on the metabolizability, but the mean metabolizability of glycerol was $89.9 \pm 3.8 \%$. 
Table 1. Expt $\mathrm{r}$. Total heat production, heat increment, and efficiency of utilization of acetate infused into the rumen of sheep

(Mean values with their standard errors for six observations)

\begin{tabular}{|c|c|c|c|c|}
\hline \multirow[b]{2}{*}{ Infusion method } & \multicolumn{2}{|c|}{ 'Tota1 heat production $(\mathrm{kcal} / \mathrm{d})$} & \multirow{2}{*}{$\begin{array}{c}\text { Heat } \\
\text { increment } \\
(\mathrm{kcal} / \mathrm{d})\end{array}$} & \multirow{2}{*}{$\begin{array}{c}\text { Efficiency of } \\
\text { utilization } \\
(\%)\end{array}$} \\
\hline & Saline & Acetate & & \\
\hline Continuous & $\begin{array}{r}1744^{\circ} 9 \\
\pm 12.6\end{array}$ & $\begin{array}{l}\text { I } 880^{\circ} 4^{* * *} \\
\quad \pm 9 \cdot 1\end{array}$ & $\begin{array}{l}\text { I } 33^{\circ} 4^{*} \\
\pm 7.6\end{array}$ & $\begin{array}{l}63.0^{*} \\
\pm 2.1\end{array}$ \\
\hline Rapid & $\begin{array}{r}1757 \cdot 3 \\
\pm 13.3\end{array}$ & $\begin{array}{l}\operatorname{Ig} 28 \cdot 7^{* * *} \\
\pm \mathrm{I} 2 \cdot 2\end{array}$ & $\begin{array}{l}\text { I } 73.5 * \\
\pm \text { I } 2.5\end{array}$ & $\begin{array}{l}51 \cdot 8 * \\
\pm 3 \cdot 5\end{array}$ \\
\hline
\end{tabular}

This value was used to correct the gross energy of the glycerol in subsequent calculations concerning the efficiency of utilization of ME provided by glycerol.

Efficiency of utilization of acetate $($ Expt $\mathrm{I})$. To calculate the heat increment incident to acetate infusion and the respective efficiency with which the energy provided by acetate was utilized for body gain, it was necessary to estimate what the heat production would have been if no acetate had been infused. This was done by formulating a regression equation relating the heat-production values obtained during the salinecontrol and saline-recovery periods and the number of days of experimentation. The regression equation was used to predict the non-acetate additive heat production on any day during the acetate-infusion period, which came between the saline-control and saline-recovery periods.

The results concerned with the utilization of acetate for body energy gain in Expt $\mathbf{I}$ are summarized in Table $\mathrm{I}$. The rapid infusion of acetate resulted in a higher heat increment $(P<0.05)$ and, consequently, a lower efficiency of energy utilization $(P<0.05)$ than did the continuous infusion.

In order to determine whether the efficiency with which acetate energy was utilized for body gain was related to the time that had elapsed after the beginning of the infusion, regression coefficients expressing the rate of change in total heat production with time elapsed were computed for both methods of infusion during the acetateand saline-infusion periods. This examination revealed that the regression coefficients for neither the values obtained during the saline-infusion periods nor those obtained during the acetate-infusion period were significantly different from zero. Since the daily amount of acetate infused throughout the $28 \mathrm{~d}$ period was constant, it was concluded that there was no change in the heat increment or in efficicncy of utilization over the time period studied.

Efficiency of utilization of glycerol and acetate (Expt 2). The results obtained in Expt 2 were treated similarly to those obtained in Expt I, except that the heatproduction values observed during the saline-infusion periods were used to compute a regression equation by means of which the non-additive heat production could be estimated for any day during the glycerol +saline or glycerol + acetate infusion periods. Also, the heat-production values for the glycerol + saline period were used 
Table 2. Expt 2. Total heat production, heat increment and efficiency of utilization of glycerol infused into the rumen of sheep

(Mean values with their standard errors for six observations)

\begin{tabular}{|c|c|c|c|c|}
\hline \multirow[b]{2}{*}{ Infusion method } & \multicolumn{2}{|c|}{ Total heat production (kcal/d) } & \multirow[b]{2}{*}{$\begin{array}{c}\text { Heat } \\
\text { increment } \\
(\mathrm{kcal} / \mathrm{d})\end{array}$} & \multirow[b]{2}{*}{$\begin{array}{c}\text { Efficiency of } \\
\text { utilization } \\
(\%)\end{array}$} \\
\hline & Saline & $\begin{array}{l}\text { Glycerol + } \\
\text { saline }\end{array}$ & & \\
\hline Continuous & $\begin{array}{r}1864.5 \\
\pm 5.6\end{array}$ & $\begin{array}{r}1922.3 \\
\pm 13.8\end{array}$ & $\begin{array}{r}577 \\
\pm 134\end{array}$ & $\begin{array}{r}70 \cdot 3 \\
\pm 6 \cdot 9\end{array}$ \\
\hline Rapid & $\begin{array}{l}1839^{\circ} 6 \\
\pm I 4^{\circ}\end{array}$ & $\begin{array}{r}1913.2 \\
\pm 9.8\end{array}$ & $\begin{array}{r}73.6 \\
\pm 10.8\end{array}$ & $\begin{array}{r}62 \cdot 2 \\
\pm 5 \cdot 6\end{array}$ \\
\hline
\end{tabular}

Table 3. Expt 2. Total heat production, heat increment, and efficiency of utilization of acetate infused into the rumen of sheep

(Mean values with their standard errors for six observations)

\begin{tabular}{|c|c|c|c|c|}
\hline \multirow[b]{2}{*}{ Infusion method } & \multicolumn{2}{|c|}{ Total heat production (kcal/d) } & \multirow{2}{*}{$\begin{array}{c}\text { Heat } \\
\text { increments } \\
(\mathrm{kcal} / \mathrm{d})\end{array}$} & \multirow{2}{*}{$\begin{array}{c}\text { Efficiency of } \\
\text { utilization } \\
(\%)\end{array}$} \\
\hline & $\begin{array}{c}\text { Glycerol }+ \\
\text { saline }\end{array}$ & $\begin{array}{c}\text { Glycerol }+ \\
\text { acetate }\end{array}$ & & \\
\hline Continuous & $\begin{array}{r}1922 \cdot 3 \\
\pm 13 \cdot 8\end{array}$ & $\begin{array}{r}2038 \cdot 2 \\
\pm 7 \cdot 2\end{array}$ & $\begin{array}{l}\text { I I } 5 \cdot 0 * \\
\pm 7.5\end{array}$ & $\begin{array}{c}68 \cdot I * \\
\pm 2 \cdot I\end{array}$ \\
\hline Rapid & $\begin{array}{r}\text { r9r } 3 \cdot 2 \\
\pm 9.8\end{array}$ & $\begin{array}{r}2067 \cdot 3 \\
\pm 13 \cdot 1\end{array}$ & $\begin{aligned} & \text { I } 51 \cdot 8 * \\
\pm & \text { I I. } 8\end{aligned}$ & $\begin{array}{c}57 \cdot 9^{*} \\
\pm 3 \cdot 3\end{array}$ \\
\hline
\end{tabular}

* Significantly different $(P<0.05)$ within criterion.

to formulate a regression equation by which the non-acetate heat production could be estimated for any day during the glycerol + acetate infusion period. As a consequence, the efficiency with which acetate was utilized in the presence of glycerol could be studied.

A summary of the results concerned with the efficiency of utilization of glycerol is recorded in Table 2. As a consequence of the small amount of glycerol infused (equivalent to $216 \mathrm{kcal}(904 \mathrm{~kJ})$ gross energy/d, of which $18 \mathrm{I} \mathrm{kcal}(757 \mathrm{~kJ}) / \mathrm{d}$ were metabolizable) and the correspondingly high standard errors, the difference between the efficiency of utilization for body gain when glycerol was infused continuously $(70 \cdot 3 \pm 6 \cdot 9 \%)$ and when it was rapidly infused $(62 \cdot 2 \pm 5.6 \%)$ did not approach statistical significance. Regression analysis of the results revealed that no significant change in the efficiency of glycerol utilization occurred with increasing duration of the infusion period.

To estimate the efficiency with which acetate was utilized in the presence of glycerol, the heat-production values obtained during the glycerol + saline infusion period were used as the base-line. In so doing, the assumption was made that the utilization of the glycerol was not affected by the presence of the added acetate. The summary recorded in Table 3 shows that the calorimetric efficiency of acetate in the presence of glycerol was $68 \cdot \mathrm{I} \pm 2 \cdot 1 \%$ under conditions of continuous infusion and $57.9 \pm 3.3 \%$ when the infusions were rapid $(P<0.05)$. The magnitude of the 
Table 4. Summary of energetic efficiencies observed with different additives infused into the rumen of sheep

(Mean values with standard errors for six observations)

\begin{tabular}{|c|c|c|c|c|}
\hline \multirow[b]{2}{*}{ Infusion method } & \multicolumn{4}{|c|}{ Energetic efficiency of utilization $(\%)$} \\
\hline & Acetate & Glycerol & Acetate & Combinedf \\
\hline Continuous & $\begin{array}{r}63 \cdot 0 \\
\pm 2.1\end{array}$ & $\begin{array}{r}70.3 \\
\pm 6.9\end{array}$ & $\begin{array}{r}68 \cdot I \\
\pm 2 \cdot I\end{array}$ & $\begin{array}{r}68.8 \\
\pm I^{\prime} \cdot 4\end{array}$ \\
\hline Rapid & $\begin{array}{r}51.8 \\
\pm 3.5\end{array}$ & $\begin{array}{r}62 \cdot 2 \\
\pm 5.6\end{array}$ & $\begin{array}{r}57.9 \\
\pm 3.3\end{array}$ & $\begin{array}{r}58.6 \\
\pm 2.0\end{array}$ \\
\hline
\end{tabular}

* Acetate infused alone (Expt I).

$\dagger$ Efficiency computed for energy of acetate alone when acetate was infused in presence of glycerol (Expt 2).

$\ddagger$ Efficiency computed for utilization of total cnergy of acetate and glycerol (Expt 2 ).

difference attributable to the method of infusion was similar to that observed in Expt I, in which acetate was infused alone.

Table 4 summarizes the calorimetric efficiencies of the various additives for body gain, and it includes the efficiency with which the energy of glycerol + acetate (Expt 2) was utilized. By subjecting the results to a regression analysis of total heat production on time elapsed after the beginning of the infusion, it was found that, although the rapid infusion of glycerol + acetate resulted in a higher heat production at the start of the infusion period $(P<0.05)$, the heat production decreased significantly $(P<0.05)$ during the $28 \mathrm{~d}$ period, and at the end there was no statistical difference in heat output attributable to the method of infusion. The efficiencies with which the energy of the glycerol + acetate was utilized on days 4 and 28 were 52.4 and $63.9 \%$ respectively when infused rapidly, and 67.6 and $69.8 \%$ when infused continuously. There was therefore no change in the calorimetric efficiency of glycerol +acetatc with duration of time associated with the continuous infusion method.

Mean ME requirement of maintenance and net utilization of $M E$ for body gain. Since there were no significant differences among the efficiencies of utilization of ME provided by the basal diet with or without the various additives, the total values were pooled to estimate the mean maintenance requirement and efficiency of utilization of $\mathrm{ME}$ for body gain. The regression of body-energy gain on the intake of ME resulted in the following equation: $Y=0.568 X-49^{\cdot} \mathrm{I}$; where $Y=$ energy gain in $\mathrm{kcal} / \mathrm{kg}^{0.73}$ per d, and $X=\mathrm{ME}$ intake in $\mathrm{kcal} / \mathrm{kg}^{0.73}$ per d. The standard error of estimate $(S y . x)$ was $4 \cdot 4 \mathrm{kcal} / \mathrm{kg}^{0.73}$ per $\mathrm{d}$.

These results indicate that an average of $56.8 \%$ of the ME ingested above maintenance was retained by the sheep ingesting the diets used in these experiments. At body-energy equilibrium (i.e. when $Y=0$ ), $X=86.5 \mathrm{kcal} / \mathrm{kg}^{0.73}$ per d; this represents the mean ME requirement of maintenance. 


\section{DISCUSSION}

The experimental design, treatments and methods used were chosen to incorporate in one study certain features of previous experiments in ways that might help to account for the different conclusions published in the literature regarding the calorimetric efficiency of the metabolites absorbed by ruminants. For example, in some of the previous studies (Elliot et al. Ig65; Orskov \& Allen, I966a,b,c; Ørskov et al. I966; Bull et al. I970) in which acetic acid was utilized for body gain at a relatively high level of efficiency, the source of acetic acid was added to the basal diet which was given in discrete meals. In the experiments (Armstrong \& Blaxter, $1957 b, 1961$ ) in which the calorimetric efficiency of acetic acid was low, the basal diet was also meal-fed but the acetic acid was continuously infused into the rumen. Accordingly, in the present experiments, it was intended that the rapid infusion of acetate or other additives would simulate the expected abrupt release in those experiments in which the additive was mixed in the meal-fed diet. The continuous infusion of the acetate-acetic acid mixture and other additives and the meal-feeding of the basal diet in the present studies were similar to the methods used in the experiments of Armstrong \& Blaxter (I957 $b$, I96I). In the present study of glycerol infused alone or with acetate, it was intended to examine the effect which glycerol might have had in the experiment reported by Bull et al. (1970) who used triacetin as the source of acetic acid.

From the calorimetric results obtained in the present experiments, the overwhelming conclusion is that, irrespective of the method of infusion or of the presence or absence of glycerol, the efficiency of utilization of the energy of acetate is substantially greater than that reported by Armstrong \& Blaxter (r957 b). In fact, the calorimetric efficiency of the utilization of acetate for lipogenesis obtained in our experiments is similar to that reported by those authors for propionic acid or butyric acid. The value $(68 . \mathrm{I} \%)$ derived for acetate infused continuously in the presence of glycerol is similar to that $(7 \mathrm{I} \cdot 2 \%)$ obtained by Bull et al. (I970) as the result of whole-body analysis of sheep given triacetin as a source of acetic acid.

However, glycerol infused alone was more efficiently utilized than acetate infused alone. When glycerol is infused into the rumen of sheep, it is unlikely that the metabolic effects in the animal are the result of glycerol per se, but rather that they are the result of glycerol conversion in the rumen into fatty acids, largely propionic acid, and other metabolites, including lactic and succinic acids (Johns, 1953; Hobson \& Mann, I96r; Garton, I963). If glycerol is converted mainly into propionic acid, this would imply that the energy of propionic acid is better utilized than the energy derived from acetate, a conclusion that agrees with that of Armstrong \& Blaxter (1957 $b, \mathrm{r} 96 \mathrm{I})$. Nevertheless, the difference in efficiency between continuously infused acetate and glycerol observed in the present study $(7 \cdot 3$ percentagc units $)$ is relatively small compared with the difference in efficiency between acetate and propionate (23.4 percentage units) reported by Armstrong \& Blaxter (I957 $b$, 196I).

In our second experiment, in which acetate utilization was measured in the presence of glycerol, the mean calorimetric efficiency was $68.1 \%$ for the continuous infusion 
and only $57.9 \%$ for the rapid, bricf infusions. However, the efficiency of acetate utilization under the rapid-infusion conditions increased throughout and reached the same level of efficiency as the continuously infused acetate by the 28 th day of infusion.

As the result of their studies, in which triacetin was used as the source of acetic acid, Bull et al. (1970) hypothesized that much of the conflict in the literature surrounding the energetic efficiency of acetate could be resolved if ruminants, subjected to an abrupt influx of an increased amount of acetate, underwent a metabolic adaptation to accommodate the influx of acctate. Those authors presented tentative results indicating a much higher efficiency by the 15 th day than on the 3 rd day after the feeding with a triacetin-containing diet was begun. In the present study, there was a progressive increase in the calorimetric efficiency of acetate with the time that had elapsed after the beginning of infusion when acetate in the presence of glycerol was infused rapidly after meals of the basal diet. No change in efficiency was observed when the same additives were infused continuously. Also, no change in efficiency occurred with the time that had clapsed when acetate was infused alone either continuously or rapidly. Thus, it would appear that the adaptation theory in itself is insufficient to explain the contradictory results of previous experiments.

The efficiency of glycerol and acetate both singly or together was greater when they were infused continuously than when they were infused rapidly. Experiments conducted with ruminants to determine the effect of meal-frequency on body-weight or energy gain (Gordon \& Tribe, 1952; Blaxter, Graham \& Wainman, 1956; Rakes, Lister \& Reid, r96r; Graham, 1967) or on milk production (Mochrie, Thomas \& Lucas, 1956; Campbell \& Merilan, 1960) have yielded somewhat conflicting results; though in one experiment (Campbell \& Merilan, 1960), in which a greater response was associated with frequent meals, the effect was confounded by different food intakes and composition at the various feeding frequencies. However, in the experiments of Rakes et al. (196r) and Graham (1967) in which equicaloric amounts of the same diet were given at different meal frequencies to sheep, the net energetic efficiency was highcr when the meals were given more frequently. Although in the present study the basal diet was given twice each day at $\mathbf{I} 2 \mathrm{~h}$ intervals irrespective of the infusion method, the method of rapid infusion of the additives during the I $h$ period after feeding with the basal diet resembled an infrequent-meal regimen and the method of continuous infusion of the additives resembled a frequent-meal regimen. As with the frequent-meal treatment in other experiments, the continuous infusion of the additives in the present study resulted in a higher energetic efficiency. However, this effect is opposite in direction to that required to explain the conflicting results in the literature concerning acetate utilization, since the low efficiency of acetate utilization reported by Armstrong \& Blaxter (1957 $b$, 1961) was observed by them in experiments in which acetate was infused continuously. 


\section{REFERENCES}

Association of Official Agricultural Chemists (I 960). Official Methods of Analysis gth ed. Washington, DC: Association of Official Agricultural Chemists.

Armstrong, D. G. \& Blaxter, K. L. (1956). Proc. Nutr. Soc. I5, i.

Armstrong, D. G. \& Blaxter, K. L. (1957a). Br. F. Nutr. II, 247.

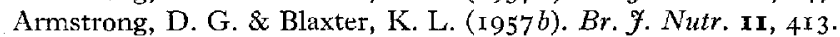

Armstrong, D. G. \& Blaxter, K. L. (т 961). Publs Eur. Ass. Anim. Prod. no. Io, p. 187.

Armstrong, D. G., Blaxter, K. L. \& Graham, N. McC. (I957). Br. F. Nutr. Ir, 392.

Armstrong, D. G., Blaxter, K. L. \& Graham, N. McC. (I96I). Br. F. Nutr. 15, I60.

Armstrong, D. G., Blaxter, K. I. \& Graham, N. McC. \& Wainman, F. W. (1958). Br. F. Nutr. 12, I 77 .

Blaxter, K. L., Graham, N. McC. \& Wainman, F. W. (1956). Proc. Nutr. Soc. r5, ii.

Bull, L. S., Reid, J. T. \& Johnson, D. E. (1970). F. Nutr. 100, 262.

Campbell, J. R. \& Merilan, C. P. (1960). F. Dairy Sci. 43, 872.

Elliot, J. M., Hogue, D. E., Myers, G. S. Jr \& Loosli, J. K. (1965). F. Nutr. 87, 233.

Garton, G. A. (1963). In Progress in Nutrition and Allied Sciences p. 69 [D. P. Cuthbertson, editor]. Edinburgh: Oliver and Boyd.

Gordon, J. G. \& Tribe, D. E. (1952). Br. Y. Nutr. 6, 89.

Graham, N. McC. (1967). Aust, $¥$. agric. Res. 18, 467 .

Hobson, P. N. \& Mann, S. O. (I961). F. gen. Microbiol. 25, 227.

Johns, A. 'I'. (I953). N.Z. Fl Sci. Technol. A 35, 262.

Mochrie, R. D., Thomas, W. E. \& I ucas, H. L. (1956). 7. Anim. Sci. 15, 1256.

Orskov, E. R. \& Allen, D. M. (1966a). Br. F. Nutr. 20, 295.

Ørskov, E. R. \& Allen, D. M. (1966b). Br. \%. Nutr. 20, 509.

Ørskov, E. R. \& Allen, D. M. (I g66c). Br. F. Nutr. 20, 5 I9.

Orskov, E. R., Hovell, F. D. \& Allen, D. M. (1 966). Br. 7. Nutr. 20, 307.

Rakes, A. H., Lister, E. E. \& Reid, J. T. (1961). F. Nutr. 75, 86. 